Boise State University

ScholarWorks

$4-1-2015$

Increasing Rural Special Education Teacher Candidates' Ability to Implement Evidence-Based Practices: A Program Description of the Boise State University TATERS Program

Evelyn S. Johnson

Boise State University 


\title{
Increasing Rural Special Education Teacher Candidates' Ability to Implement Evidence-Based Practices: A Program Description of the Boise State University TATERS Program
}

\author{
Evelyn S. Johnson \\ Boise State University
}

\begin{abstract}
The Technology Accentuated Teacher Education for Rural Specialists (TATERS) program aimed to: (a) prepare highly qualified special education teachers across a state comprised of more than $70 \%$ rural districts, (b) develop a system of support through a mentor network and institutions of higher education collaboration to address the needs of teacher candidates in rural areas, (c) ground special education teachers in the use of evidence-based practices to improve the instructional services that students with disabilities in Idaho receive, and (d) develop a mechanism to evaluate and provide feedback on teacher candidates' implementation of evidence-based practices. This article describes the application of a special education teacher evaluation system to a teacher preparation program designed to improve special education teachers' ability to implement evidence-based practices for students with disabilities in rural areas. Key program components are described and future directions for continuous improvement are highlighted.
\end{abstract}

Keywords: special education teacher preparation, evidence-based practice implementation, online teacher preparation

Students with disabilities (SWD) are arguably the most difficult students to teach. They need individually designed instruction to meet their unique learning needs, and the delivery of this type of instruction requires a highly trained, analytical special education teacher who thoroughly understands the content or construct she is teaching, can assess where the student is in the learning progression, and effectively delivers instruction using methods that support the student's learning needs. The effective use of evidence-based practices (EBPs) is a sophisticated iterative process, leading some to refer to special education instruction as a technical science (Odom et al., 2005) that requires a high level of training and preparation of special education teachers. Unfortunately, SWD are more often served by a special education teaching force that is not well trained in the use of EBP, and that is highly subject to attrition and turnover (Billingsley, 2004; Boe, Cook, \& Sunderland, 2008; Connelly \& Graham, 2009).

Special education is consistently identified as a high demand field with positions filled by teachers who lack adequate preparation to meet the demands of the position (Boe et al., 2008). This is especially the case in rural states such as Idaho, where special education has been identified as a high demand field for nearly three decades. The hard to fill nature of this position is not easily solved. The shortage of highly qualified teachers has led to an increased number of teachers accepting positions even though they are not qualified and then completing alternative routes to certification with various levels of quality. The net effect is a special education teacher workforce that has contributed to the poor academic outcomes for SWD. For example, recent estimates suggest that as little as $20 \%$ of a special education teacher's time is dedicated to instruction (Vannest \& Hagan-Burke, 2009) and that as few as 30\% of SWD are able to meet performance standards (Odom, 2009). Consequently, ill-prepared teachers who are doing their best to learn 'on the job' then serve as 'model' teachers for candidates who are completing their special education teacher certification program. This means that many teacher candidates do not have access to one of the critical components of an effective teacher education systemstrong field experiences where they are able to learn, practice, and receive feedback on their use of EBPs that support the needs of students with disabilities. Improving special education teacher practice requires a systems level change that includes multiple components, including stronger special education teacher preparation programs that effectively produce teachers well-versed in implementing EBPs.

\section{Challenges of Teacher Preparation in Rural Districts}

Rural districts face many challenges. First, rural districts generally do not have ready access to universities, where they can collaborate with teacher education programs and hire promising graduates. Second, they have difficulty recruiting highly qualified teachers to move to rural areas because they cannot match pay, many people do not want to move

The contents of this article were developed under a grant from the US Department of Education, H324T080003. However, these contents do not necessarily represent the policy of the US Department of Education, and you should not assume endorsement by the federal government or Project Officer, Tina

Diamond. Please address all correspondence to Evelyn S. Johnson (evelynjohnson@boisestate.edu). 
to rural areas, or they do not have strong professional support systems and induction programs, including access to mentor teachers who are available to answer questions and to support the use of EBPs (Hardman, Rosenberg \& Sindelar, 2005). To fill vacancies, rural districts must often resort to hiring teachers who are not certified (Menlove \& Lignugaris/Kraft, 2004). These teachers either complete teacher training programs while they are busy with the demands of a new job or, in many cases, leave the profession before their emergency credential expires. The cycle of less than optimal instruction that is provided to SWD is difficult to break under these circumstances.

Critical shortages of special education teachers exist in many areas of the nation but are especially pronounced in rural areas (Menlove \& Lignugaris/Kraft, 2004), where filling positions is problematic. The need for highly skilled, well-trained special education teachers in rural areas to deliver intensive, individualized instruction to support a child's academic growth cannot be overstated. Classroom observation studies repeatedly indicate that students do not always receive services that can reasonably be expected to mitigate the effects of their disabilities (Morgan, Frisco, Farkas \& Hibel, 2008). Other researchers have found special education classroom instruction to be routine and generic to all students in the class, rather than intensive and individualized as articulated in each student's IEP (Harry \& Klingner, 2006). Recent classroom observations in rural districts indicate that low levels of EBP implementation is the norm; a collection of teacher observations used to validate a special education teacher observation tool indicated that $100 \%$ of participating special education teachers were rated as basic or below on their use and implementation of EBP (Johnson \& Semmelroth, in press).

As a result of the decreased access to regular, high-quality special education instruction, the academic achievement for SWD has either declined or not improved in spite of the range of evidence-based instructional practices that have been established in special education. Morgan et al. (2008) found that special education services from 2002-2004 had negative or statistically non-significant effects on young children's reading and mathematics skills. Nationally, the non-achieving trend has held steady for the past decade, with average scores on the National Assessment of Educational Progress measures ranging from $61 \%$ to $72 \%$ below the basic level for 4 th and 8th grade SWD (US Department of Education, 2011).

One way that the US Department of Education is seeking to remedy these challenges is through the Office of Special Education Program's (OSEP) Personnel Preparation grants. These grants provide support to Institutions of Higher Education (IHE) to develop special education teacher training programs that are innovative and responsive to the needs confronting K-12 schools. Through the personnel preparation programs, IHEs are encouraged to ensure that EBPs are integrated in their teacher preparation coursework to produce highly qualified special education teachers who are ready to support the needs of SWD.

\section{Program Structure and Beneficiaries}

The OSEP funded special education teacher preparation program at Boise State University, Technology Enhanced
Teacher Education for Rural Specialists (TATERS) was designed to help address several significant needs in Idaho: (a) Prepare highly qualified special education teachers across a state comprised of more than $70 \%$ rural districts, (b) develop a system of support through a mentor network and IHE collaboration to address the needs of teacher candidates in rural areas, (c) ground special education teachers in the use of EBPs to improve the instructional services that students with disabilities in Idaho receive, and (d) develop a mechanism to evaluate and provide feedback on teacher candidates' implementation of EBPs so they enter the profession with the highest possible skill level.

The program was designed as a post-baccalaureate certification option that has since evolved into a graduate level Master's in Teaching program. Graduates of our revised special education teacher preparation program included not only teacher candidates in the surrounding Boise area, but also 27 graduates serving in rural districts across the state of Idaho.

\section{Key Components of TATERS}

TATERS is guided by the critical features of effective teacher preparation programs outlined by Brownell, Ross, Colon and McCallum (2005) that includes: (a) a common and coherent vision of teaching and learning, (b) common and related strategies across courses, (c) integrated clinical experience with coursework, and (d) revisiting 'big ideas' continuously throughout the program. The TATERS program is offered online over four semesters. In addition to the online coursework, teacher candidates complete intensive fieldwork each semester that is focused on supporting their application of the EBPs they learn in class to their K-12 classrooms. Over the 5 years of our program, we worked with a consistent set of supervising teachers and worked with the Idaho State Department of Education to develop a special education teacher mentor network. The specifics of our coursework and mentor program are outlined in more detail elsewhere (see Johnson, Humphrey, \& Allred, 2009).

In the first 2 years of the TATERS program, our focus was on the first three critical features (Brownell et al., 2005) listed above. In addition to having program level assignments that cut across courses (e.g. teacher candidates began the process of IEP development in the assessment course, then learned to develop goals and objectives in methods, behavior and transition courses), we also ensured the consistency of our online course design and format to allow our teacher candidates to focus on content rather than having to learn how to navigate a new course set up. We also developed integrated field assignments designed to serve as complex performance assessments during which our teacher candidates synthesized and applied the specific information they learned to the K-12 classroom setting. In the third year of our program, we realized that our teacher candidates needed more guided practice and feedback with EBP implementation and that we needed to develop an evaluation system to serve as a formative and summative assessment of candidate performance in their field experiences. Working with our state department of education, we developed a special education teacher evaluation system that we were able to apply to our preservice teacher candidates (Johnson \& Semmelroth, 2014). 


\section{Evaluating Teacher Candidates' Use of EBP}

Online coursework coupled with intensive field experiences is a common model for special education teacher preparation programs serving large geographical areas. Our concern as we continued with TATERS implementation was that many of our teacher candidates were working either in less than optimal placements (e.g., partnered with a teacher who had little or no training and experience in special education) or filling both the role of K-12 special education teacher and TATERS special education teacher candidate and, as a result were lacking sufficient practice and feedback on their implementation of various instructional practices. With the funding support from the OSEP 325T grant, we hired a program coordinator who maintained contact with our teacher candidates and conducted two observations each semester. Given that one of the goals of the OSEP personnel preparation program is to ensure sustainability after grant funding ends, we needed to find a way to increase our ability to conduct observations in a cost-effective way.

To remedy this issue, we worked with the Idaho State Department of Education to develop a special education teacher evaluation system that included evaluation tools for pre-service, initial certification, and master special education teachers. The teacher evaluation tool we designed was called Recognizing Effective Special Education Teachers (RESET) and is described in more detail in Johnson \& Semmelroth (2014). In brief, RESET relies on the observation of special education teachers' instruction and, using rubrics that are aligned with EBP criteria, provides a rating of performance but, more important, provides specific and actionable feedback on how to improve instructional practice. A significant body of research establishes a number of effective practices to meet the needs of SWD. Aligning the evaluation system to provide feedback on the specifics of these practices provides teachers the information needed to improve. RESET is based on the following principles:

1. The system is grounded in Danielson's framework with a focus on Domain 3: Instruction (Danielson, 2007). In addition to evaluating common features of sound instructional practice, it includes much more clearly delineated criteria for evaluating evidence-based instructional practice appropriate for SWD.

2. The evaluation system is computerized and uses video capture of a teacher candidate's instruction. The video is evaluated by a faculty supervisor, the teacher candidate, and, when possible, the mentor teacher.

3. Special education teacher candidates receive feedback according to the criteria derived from the research establishing instruction as evidence-based.

4. The increased use of EBP will ultimately lead to improvements in outcomes for SWD. Teacher candidates monitor and report their students' growth so that, over time, student growth and achievement might be used as a reasonable estimate of a teacher's effective implementation of EBP.

Our evaluation focused primarily on instruction because it is the single variable within a special education teacher's control that most affects student outcomes. Drawing on the research on instructional practice to date, we identified com- mon elements of instruction, such as (a) building effective instruction based on rigorous expectations, (b) creating an effective learner environment that is engaging, (c) making content area knowledge relevant to the learner, and (d) providing learning experiences using effective research based strategies (Hattie, 2009). Next, we identified the specific instructional practices within special education that have been determined to be EBP. A significant body of research has established a number of effective instructional practices to meet the needs of students with disabilities (see, for example, Chard, Ketterlin-Geller, Baker, Doabler, \& Apichatabutra, 2009; Cook \& Odom, 2013; Fuchs \& Fuchs, 2005; Gersten et al., 2009; National Autism Center, 2009; Odom, 2009; Spooner, Knight, Browder, \& Smith, 2012). This body of research guided the development of detailed rubrics used to evaluate practice and to provide guidance to teacher candidates.

The conceptual framework guiding the use of RESET in teacher training programs is that, through a targeted, welldefined observation that incorporates clearly explicated criteria linked to EBPs in special education, teacher candidate attention will be targeted to those instructional practices that have been demonstrated to result in improved student outcomes. Through the use of this evaluation rubric, teacher candidates are provided with explicit feedback on the components of instructional practices on which they need improvement. In addition, teacher candidates routinely collect, analyze and react to individual student data. When this practice is coupled with the use of RESET within the teacher preparation program, our teacher candidates begin to better understand the impact of their instructional practice on student outcomes. As an evaluation system for special education teacher candidates, the focus of RESET is on its formative rather than summative use. The observation system and feedback is designed to help our teacher candidates improve their instructional practice.

\section{Process of Teacher Candidate Evaluation}

As mentioned above, the focus of RESET was on its use as a formative assessment. Teacher candidates were required to videotape a minimum of four lessons throughout the semester. Initially, we used the Teachscape video system (which was used as part of the development of RESET), but access to a limited number of cameras meant that we needed the ground staff to set up, operate, and capture the video recordings. As part of our sustainability efforts, we knew that continued reliance on Teachscape was not feasible and so elected to use lower cost alternatives for video capture, such as personal mobile devices (e.g., smartphone, iPad). Videos were then uploaded to a secure system, and viewed and evaluated asynchronously by the program coordinator and teacher candidate, with time allotted for synchronous, virtual debriefing meetings.

The RESET tool produces a score when used to evaluate special education teachers, and ongoing work is examining cut scores and proficiency levels (Johnson \& Semmelroth, in press). When applied to special education teacher candidates, we did not assign score values, relying only on the use of feedback on the specific instructional components. Our decision to avoid the use of scores with our candidates was intentional. The RESET scoring system is still being validated, and therefore, we did not want to make decisions about 
candidate performance using flawed data. In addition, our goal in using RESET was to provide multiple opportunities for a teacher candidate to practice and receive feedback on their implementation of an EBP. We were concerned that assigning a score would take the emphasis away from improving practice and place it on trying to 'pass a test.' Finally, one of the values of our program is engaging in continuous improvement. Our goal with repeated observation was to instill this value into our teacher candidates as a lifelong professional practice.

The feedback session was individualized to address each candidate's specific needs. However, we followed a common format and framework for guiding the discussion. First, we asked the candidate to discuss their self-evaluation. The rubric criteria served as a common and consistent reference for teacher candidates and allowed them to focus their thoughts and discussion. Next, the supervising faculty provided their evaluation. Discrepancies in the evaluation were discussed to ensure common understandings. When available, the mentor teacher also engaged in this process. Each feedback session was concluded with a 'next steps' list of specific, actionable items for the teacher candidate to work on, and these items were reviewed in the subsequent session.

\section{Program Outcomes and Next Steps}

We did not begin the use of RESET in our TATERS program until the fourth year of implementation. Prior to that, our state did not have a special education teacher evaluation system, and, as a department, we were still updating coursework, establishing relationships with coordinating sites, developing our mentor network system, and devising the evaluation system. Therefore, our current data on the use of the RESET system within our teacher preparation program is still anecdotal in nature, as it is based on information collected from 10 special education teacher candidates. However, the information collected to date provides important feedback for other programs considering the use of similar models and for determining next steps.

\section{Teacher Candidate Response to Evaluation Systems}

Our teacher candidates responded very favorably to the video-recorded observation and feedback of their instructional practice. Nearly all of our candidates indicated that observing themselves on video was one of the most effective instructional processes used in our TATERS program. In addition, they noted that the use of rubrics outlining the key elements of an EBP were especially helpful in guiding their practice. The rubrics provide a concise guide that mirrored what they learned in coursework so that they could understand how the instructional method should be translated into practice. The cohort of teacher candidates who used video observations and feedback via RESET took ownership of the process as the semester continued, oftentimes being able to identify with minimal input from program staff the instructional practices that were effective and areas that needed continued refinement.

\section{Faculty Response to Evaluation Systems}

To date, only two program staff have routinely used video observations and feedback provided via RESET. While the initial set up and process can seem cumbersome, over time, both program staff indicated that the significant advantage in using RESET to evaluate candidate performance was the analytic and reflective focus it brought to the observation sessions and, as a result, the significant improvement in teacher candidate performance that was realized. In addition, the focus on ensuring that teacher candidates mastered EBPs contributed to a revision of the program with increased emphasis on the use of a concentrated set of EBPs designed to meet the needs of many SWD; thus, teacher candidates who enter the program will be trained to effectively implement a core set of EBPs and then expand their repertoire through professional practice and the state's tiered licensure professional development requirements.

The use of the evaluation system helped to connect multiple components of our special education teacher preparation system. First, by aligning our teacher candidate observation system with a tool that will be used by the state to evaluate them as practicing teachers, we are able to focus the IHE's role in the teacher preparation process, ensuring that our graduates are prepared to meet the demands of their new positions. In addition, the use of the observation tool to evaluate practice served as a way for faculty to bring together the elements of our program and provide a performance assessment that addresses all of the competencies our special education teachers need to demonstrate into a complex performance assessment. Finally, as a means for addressing current quality concerns in existing special education classrooms, RESET holds promise. In two classrooms in which we used RESET, the mentor teachers benefitted from the process. Both teachers requested that we use RESET to observe and provide feedback on their instructional practices.

\section{Conclusions}

Special education is a high demand field, with many positions either vacant or filled with unqualified personnel (Billingsley, Fall \& Williams, 2006; Boe \& Cook, 2006). Special education teacher preparation programs often do not integrate the use of EBPs, leaving new teachers ill-prepared to meet the challenges of the classroom (Reschly, Holdheide, Smart \& Oliver, 2007). Historically, special education has been characterized by high attrition rates (Holdheide, Goe, Croft, \& Reschly, 2010; Sindelar, Brownell, \& Billingsley, 2010) and personnel who are not fully certified or certified through alternate routes (Littrell, Billingsley, \& Cross, 1994; McLeskey, Tyler, Saunders, \& Flippin, 2004). These factors lead to a profession chronically faced with teacher shortages, as evidenced by surveys in which more than $95 \%$ of all US school districts reported at least one teaching vacancy in the field of special education at the beginning of the school year (Connelly \& Graham, 2009). Given the increase in students receiving special education of over $30 \%$ in the past decade, the problem continues to grow. The combination of these challenges has contributed to the "substandard quality of education for students with special needs" (CEC Launches Initiatives on Special Education Teaching Conditions, 1998, as cited by Gersten, Keating, Yovanoff, \& Harniss, 2001, p. 549).

Teacher preparation programs can serve as an effective tool in remedying the challenges that the special education 
field confronts. Through the implementation of a teacher candidate observation system that both informs and evaluates teacher candidates on their use of evidence-based instructional practices, special education teacher candidates will be provided ongoing opportunities to develop competency with their work. Over time, the system can encourage special education teacher programs to prioritize and teach the use of instructional practices that are most likely to bring about improved student outcomes (Cook, Tankersley, \& Landrum, 2009). Our initial experience integrating the use of an observation system designed to provide feedback on teacher candidates' implementation of EBP within our teacher preparation program suggests that it can have a positive effect on our special education teacher candidate facility with EBP implementation, as well as on the practices of mentor teachers in the $\mathrm{K}-12$ classroom.

\section{References}

Billingsley, B. S. (2004). Special education teacher retention and attrition: A critical analysis of the research literature. The Journal of Special Education, 38(1), 39 55. doi: $10.1177 / 00224669040380010401$

Billingsley, B. S., Fall, A. M., \& Williams, T. O. (2006). Who is teaching students with emotional and behavioral disorders? A comparison to other special educators. Behavioral Disorders, 31(3), 252-264.

Boe, E. E., \& Cook, L. H. (2006). The chronic and increasing shortage of fully-certified teachers in special and general education. Exceptional Children, 72(4), 443-460.

Boe, E. E., Cook, L. H., \& Sunderland, R. J. (2008). Teacher turnover: Examining exit attrition, teaching area transfer, and school migration. Exceptional Children, 75(1), 7-31.

Brownell, M. T., Ross, D., Colon, E., \& McCallum, C. (2005). Critical features of special education teacher preparation: A comparison with exemplary practices in general education. Journal of Special Education, 38, 242-251.

Chard, D. J., Ketterlin-Geller, L. R., Baker, S. K., Doabler, C., \& Apichatabutra, C. (2009). Repeated reading interventions for students with learning disabilities: Status of the evidence. Exceptional Children, 75(3), 263-281.

Connelly, V., \& Graham, S. (2009). Student teaching and teacher attrition in special education. Teacher Education and Special Education, 32(3), 257-269. doi: $10.1177 / 0888406409339472$

Cook, B. G., \& Odom, S. L. (2013). Evidence-based practices and implementation science in special education. Exceptional Children, 79(2), 135-144.

Cook, B. G., Tankersley, M., \& Landrum, T. J. (2009). Determining evidence-based practices in special education. Exceptional Children, 75(3), 365-383.

Danielson, C. (2007). Enhancing professional practice: A framework for teaching. Alexandria, Va.: Association for Supervision and Curriculum Development.

Fuchs, L. S., \& Fuchs, D. (2005). Enhancing mathematical problem solving for students with disabilities. The Journal of Special Education, 39(1), 45-57.

Gersten, R., Chard, D. J., Jayanthi, M., Baker, S. K., Murphy, P., \& Flojo, J. (2009). Mathematics instruction for students with learning disabilities: A meta-analysis of instructional components. Review of Educational Research, 79(3), $1202-1242$.

Gersten, R., Keating, T., Yovanoff, P., \& Harniss, M. K. (2001). Working in special education: Factors that enhance special educators' intent to stay. Exceptional Children, 67(4), 549-567.

Hardman, M. L., Rosenberg, M., \& Sindelar, P. (2005). NCLB, IDEA, and alternative routes in prepartation of rural special education teachers in high incidence areas. Rural Special Education Quarterly, 24(1), 16-24.

Harry, B., \& Klingner, J. K. (2006). Why are so many minority students in special education?: Understanding race $\mathbb{E}$ disability in schools. New York; London: Teachers College Press.

Hattie, J. (2009). Visible learning: A synthesis of over 800 meta-analyses relating to achievement. Taylor \& Francis

Holdheide, L., Goe, L., Croft, A., \& Reschly, D. J. (2010). Challenges in evaluating special education teachers and English language learner specialists (pp. 1-40). Washington DC.
Johnson, E. S., Humphrey, M. \& Allred K. (2009). Mentoring and online learning: A helping hand for rural districts? Rural Special Education Quarterly, 28(2), 32-38.

Johnson, E. S. \& Semmelroth, C. L. (in press). Validating an Observation Protocol to Measure Special Education Teacher Effectiveness, Journal of the American Academy of Special Education Professionals.

Johnson, E. S., \& Semmelroth, C. L. (2014). Special education teacher evaluation: Why it matters and what makes it challenging. Assessment for Effective Intervention. 39(2), 71-82.

Littrell, P. C., Billingsley, B. S., \& Cross, L. H. (1994). The effects of principal support on special and general educators' stress, job satisfaction, schoo commitment, health, and intent to stay in teaching. Remedial and Special Education, 15(5), 297-310.

McLeskey, J., Tyler, N. C., Saunders, \& Flippin, S. (2004). The supply of and demand for special education teachers: A review of research regarding the chronic shortage of special education teachers. The Journal of Special Education, 38(1), 5-21.

Menlove, R., \& Lignugaris/Kraft, B. (2004). Preparing rural distance education preservice special educators to succeed. Rural Special Education Quarterly 23(2), $18-26$.

Morgan, P. L., Frisco, M. L., Farkas, G., \& Hibel, J. (2008). A propensity score matching analysis of the effects of special education services. The Journal of Special Education, 43(4), 236-254. doi:10.1177/0022466908323007

National Autism Center (2009). National standards report. Randolph, Massachusetts. Retrieved from http://www.nationalautismcenter.org/nsp/reports.php

Odom, S. L. (2009). The tie that binds: Evidence-based practice, implementation science, and outcomes for children. Topics in Early Childhood Special Educa tion, 29(1), 53-61.

Odom, S. L., Brantlinger, E., Gersten, R., Horner, R. H., Thompson, B., $\&$ Harris, K, R. (2005). Research in special education: Scientific methods and evidence-based practices. Exceptional Children, 71(2), 137-148.

Reschly, D. J., Holdheide, L. R., Smartt, S. M., \& Oliver, R. M. (2007). Evaluation of special education teacher preparation coursework reading, behavior, and inclusive practices. Springfield, IL: Illinois State Board of Education.

Sindelar, P. T., Brownell, M. T., \& Billingsley, B. (2010). Special education teacher education research: Current status and future directions. Teacher Education and Special Education, 33(1), 8-24. doi:10.1177/0888406409358593

Spooner, F., Knight, V. F., Browder, D. M., \& Smith, B. R. (2012). Evidence-based practice for teaching academics to students with severe developmental disabilities. Remedial and Special Education, 33(6), 374-387. doi: $10.1177 / 0741932511421634$

U.S. Department of Education, National Center for Education Sciences. (2011). The nation's report card. Retrieved from http://nces.ed.gov/nationsreportcard/

Vannest, K. J., \& Hagan-Burke, S. (2009). Teacher time use in special education. Remedial and Special Education, 31(2), 126-142. doi: $10.1177 / 0741932508327459$ 
Copyright of Rural Special Education Quarterly is the property of ACRES and its content may not be copied or emailed to multiple sites or posted to a listserv without the copyright holder's express written permission. However, users may print, download, or email articles for individual use. 